\title{
A [60]fullerene nanoconjugate with gemcitabine: synthesis, biophysical properties and biological evaluation for treating pancreatic cancer
}

Paweł Nalepa' ${ }^{1}$, Robert Gawecki², Grzegorz Szewczyk ${ }^{3}$, Katarzyna Balin², Mateusz Dulski ${ }^{4}$, Mieczysław Sajewicz' Anna Mrozek-Wilczkiewicz², Robert Musioł', Jaroslaw Polanski ${ }^{1}$ (D) and Maciej Serda ${ }^{1 *}$ (D)

${ }^{*}$ Correspondence:

maciej.serda@us.edu.pl

${ }^{1}$ Institute of Chemistry, University of Silesia

in Katowice, Katowice, Poland Full list of author information is available at the end of the article

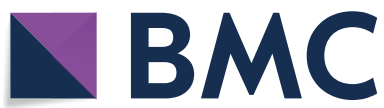

(O) The Author(s) 2020. This article is licensed under a Creative Commons Attribution 4.0 International License, which permits use, sharing, adaptation, distribution and reproduction in any medium or format, as long as you give appropriate credit to the original author(s) and the source, provide a link to the Creative Commons licence, and indicate if changes were made. The images or other third party material in this article are included in the article's Creative Commons licence, unless indicated otherwise in a credit line to the material. If material is not included in the article's Creative Commons licence and your intended use is not permitted by statutory regulation or exceeds the permitted use, you will need to obtain permission directly from the copyright holder. To view a copy of this licence, visit http://creativecommons.org/ licenses/by/4.0/. The Creative Commons Public Domain Dedication waiver (http://creativecommons.org/publicdomain/zero/1.0/) applies to the data made available in this article, unless otherwise stated in a credit line to the data. 
of cancer, targeted drug delivery systems and in vivo imaging (Chow and Ho 2013; Dawidczyk et al. 2014). The nanotechnology approach has been used by medicinal chemists to design potential drugs that can easily break through almost any biological barrier. Engineered nanoparticles, including carbon nanomaterials, can enter tumors via their leaky vessels and remain there due to the weak drainage in the tumor microenvironment. This phenomenon is called the enhanced permeability and retention effect (EPR effect) and does not occur in normal tissues (Fang et al. 2011; Maeda et al. 2016). Interestingly, in our recently published article, we demonstrated that fluorescently labeled fullerenes $\left(\mathrm{C}_{60}\right.$-serPF) can be used as a model delivery system for biodistribution studies in a breast cancer model, due to their preferred biokinetic profile (Lapin et al. 2017a).

Since their discovery in 1985, fullerene nanomaterials have drawn the attention of medicinal chemists due to their unique biological properties (Nakamura and Isobe 2003). Over the last few decades, [60]fullerenes have been investigated for many biomedical applications, including targeted drug delivery, and as contrast agents and nonviral transfection agents (Dellinger et al. 2013). The functionalization of the fullerene cage with water solubilizing groups offers a versatile method for biological experiments, as well as for conjugation with chemotherapeutic agents, fluorescent probes and cancertargeting antibodies (Zakharian et al. 2005; Ashcroft et al. 2006). Appropriately derivatized [60]fullerene buckyballs become amphiphilic in nature with the ability to cross most biological barriers, including the blood-brain barrier and nuclear membrane (Raoof et al. 2012). Furthermore, fullerene nanomaterials are non-toxic even at high concentrations of up to $1 \mathrm{mg} / \mathrm{mL}$ (Serda et al. 2018). The anti-cancer activity of fullerenes has mainly been described for in vivo models, where it has been explained by its ability to inhibit tumor angiogenesis (metalloproteinases inhibitors) and its strong antioxidant properties (Chen et al. 2005; Sun et al. 2016). Interestingly, it was described earlier that water-soluble fullerene derivatives have the ability to resensitize cancer cells that were previously resistant to cisplatin and doxorubicin (Zhang et al. 2009). The chemical functionalization of [60]fullerene using the cyclopropanation reaction, in which the derivatives of malonic acid are particularly useful (Bingel-Hirsch reaction), offers novel synthetic possibilities because it allows virtually any imaginable type of organic moiety to be covalently linked to the carbon shell of hydrophobic [60]fullerene.

Pancreatic cancer is a highly lethal disease that has a 5-year survival rate of less than $10 \%$ (Siegel et al. 2015). Currently, the most successful treatment is the surgical resection of the tumor, but in many cases, it is not possible to perform the surgery because only $20 \%$ of patients have resectable pancreatic cancer (Kamisawa et al. 2016). Thus, the development of non-surgical treatments, including adjuvant therapy, is needed in order to improve the prognosis for patients with pancreatic cancer. The first line of chemotherapeutic drugs that was used to treat pancreatic cancer was gemcitabine. The clinical trials that have been performed have shown that patients with advanced pancreatic cancer have better survival rates and durations after treatment with gemcitabine compared to those that were treated with 5 -fluorouracil (Burris et al. 1997). Moreover, combinations of gemcitabine and different chemotherapeutic agents as well as monoclonal antibodies have also been studied for advanced breast cancer (Hu et al. 2015). Nevertheless, the usefulness of the current strategies and the effects of gemcitabine monotherapy are 
hampered by its chemo-resistance, low vascularization and drug biodistribution limitations in the tumor microenvironment (Kleeff et al. 2007; Koay et al. 2014).

The use of nanoscale drugs that are designed to treat pancreatic tumors have been widely explored in the last 5 years, which has resulted in Abraxane, a nano-formulation of paclitaxel with albumin (Lee et al. 2013; Pan et al. 2015). Here, we report on a synthetic protocol that enables a water-soluble [60]fullerene nanoconjugate with gemcitabine (called nano $\mathbf{C}_{60} \mathbf{G E M}$ ) to be generated.

\section{Materials and methods Materials}

All of the compounds that were used were reagent grade or better, and the solvents were used as they were received unless otherwise specified. The following reagents were used as received: $C_{60}(99.5 \%$, SES RESEARCH, USA), gemcitabine (Sigma Aldrich), 2-amino-1,3-propanediol (AK Scientific), DBU (1,8-diaza-bicyclo[5.4.0]undec-7-ene, Sigma Aldrich), glycine (POCH, Poland), $p$-toluenesulfonic acid ( $\mathrm{POCH}$, Poland), acetic anhydride (Acros Organics), malonic acid (Acros Organics), $\mathrm{CBr}_{4}$ (Sigma Aldrich), EDCI hydrochloride [ $N$-ethyl- $N{ }^{\prime}$-(3-dimethylaminopropyl)carbodiimide hydrochloride, Acros Organics], $N$-hydroxysuccinimide (Sigma Aldrich) and sodium hydride (Acros Organics). All of the solvents that were used to prepare the carbon nanomaterials were prepared according to literature procedures by distilling them with calcium hydride and were used immediately. The nuclear magnetic resonance spectra were measured on a Bruker Avance III $500 \mathrm{MHz}$ NMR Spectrometer with TMS as the internal standard. The MS spectra for the water-insoluble fullerenes were collected using an Autoflex II MALDI-TOF mass spectrometer, and for the water-soluble [60]fullerene derivatives using an MS electrospray ionization time-of-flight (ESI-microTOF) mass spectrometer, both instruments from Bruker Daltonics Inc (Fremont, CA, USA). The final dialysis purification of the water-soluble nanomaterial nano $\mathbf{C}_{60}$ GEM was performed on Pall Microsep $^{\text {TM }}$ centrifugal membranes with molecular cut-offs 1 and $3 \mathrm{kDa}$. The purity of all of the compounds was assessed using an Agilent1260 equipped with a DAAD detector at $260 \mathrm{~nm}$, RP-column: Eclipse plus C18 $(3,5 \mu \mathrm{m})$; flow $0.5 \mathrm{~mL} / \mathrm{min}$. The Fourier transform infrared (FTIR) measurements were carried out using an Agilent Cary 640 FTIR spectrometer equipped with a standard source and a DTGS Peltier-cooled detector. The nanoconjugate powder was mixed with $\mathrm{KBr}$ and measured in the transmittance mode in the $700-4000 \mathrm{~cm}^{-1}$ range. The spectrum was recorded at 32 accumulations with a spectral resolution of $4 \mathrm{~cm}^{-1}$. The obtained data were analyzed by the baseline, water, and carbon dioxide correction. The chemical analysis of the sample surface was performed using X-ray photoelectron spectroscopy (XPS). The measurements were performed on a PHI5700 Physical Electronics spectrometer. The XPS studies were carried out with using an $\mathrm{Al} \mathrm{K \alpha}$ monochromatized X-ray source $(h v=1486.6 \mathrm{eV})$. The survey spectrum was measured at pass energy $187.75 \mathrm{e} \mathrm{eV}$, and the high-resolution core levels of C1s, F1s, N1s, O1s and Si2 were measured at pass energy $23.5 \mathrm{eV}$. The analysis of the chemical states of the detected elements, as well as the calculations of the atomic concentration was performed using MULTIPAK (version 9.6.7.1, 2015, Ulvac-phi Inc.) software. The near-infrared luminescence $(1270 \mathrm{~nm})$ was measured perpendicular to the excitation beam in the photon-counting mode using a thermoelectric-cooled NIR PMT 
module (H10330-45; Hamamatsu, Japan) equipped with a $1100 \mathrm{~nm}$ cut-off filter and an additional dichroic narrow-band filter NBP, and was selectable from the spectral range 1150-1355 nm (NDC Infrared Engineering Ltd., Essex, UK). The data were collected using a computer-mounted PCI-board multichannel scaler (NanoHarp 250; PicoQuant $\mathrm{GmbH}$, Berlin, Germany). Data analysis, including the first-order luminescence decay fitted using the Levenberg-Marquardt algorithm, was performed by custom-written software. The acquisition time for obtaining the singlet oxygen phosphorescence signals was $20 \mathrm{~s}$. The EPR measurements were taken using a Bruker EMX-AA EPR spectrometer (Bruker BioSpin, Rheinstetten, Germany). EPR samples were run using microwave power of $10.6 \mathrm{~mW}$, a modulation amplitude of $0.05 \mathrm{mT}$, center field $339.0 \mathrm{mT}$, scan width $8 \mathrm{mT}$ and scan time $21 \mathrm{~s}$. The light for photodynamic therapy was delivered from royal blue $100 \mathrm{~W}$ COB source (440 nm, FWHM 17.4 nm) (Chanzon, Shenzhen, China). The cell plate was placed in a holder above light source. Distance from the lens was set to achieve high uniformity of light power distribution on whole plate area. The cells were irradiated with $20 \mathrm{~mW} / \mathrm{cm}^{2}$ for $1000 \mathrm{~s}$ for a total dose of $20 \mathrm{~J}$. Temperature of cells during irradiation did not exceed $32{ }^{\circ} \mathrm{C}$.

\section{Methods}

\section{Synthesis of nano ${ }_{60}$ GEM}

2,2'-[(1,3-Dioxopropane-1,3-diyl)diimino]diacetic acid or malonyl-diglycine (1).

Glycine $(9.75 \mathrm{~g}, 0.130 \mathrm{~mol})$ was suspended in of $10 \mathrm{~mL}$ water and dissolved by adding $\mathrm{NaOH}$ to the solution $(5.21 \mathrm{~g}, 0.130 \mathrm{~mol})$. A solution of diethyl malonate in $30 \mathrm{~mL}$ of ethanol (10.4 g, $0.065 \mathrm{~mol}$ ) was added and the whole mixture was placed in a $100-\mathrm{mL}$ flask and heated under reflux for $3 \mathrm{~h}$. The solvent was then removed on a rotary evaporator. Then, $12 \mathrm{M}$ hydrochloric acid was being added to the residue until the $\mathrm{pH}$ of the mixture reached 1 . The flask with the mixture was placed in a refrigerator for $12 \mathrm{~h}$; during which the product precipitated. The resulting white solid was filtered off, washed with cold water and ethanol and dried. The final product was obtained as a white solid with a $19 \%$ yield $(2.83 \mathrm{~g})$ with m.p. $233^{\circ} \mathrm{C}$.

${ }^{1}$ H-NMR $\left(d_{6}-D M S O, 400 \mathrm{MHz}, p p m\right): 8.35(\mathrm{t}, J=5.8 \mathrm{~Hz}, 2 \mathrm{H}, \mathrm{NH}) ; 3.78(\mathrm{~d}, J=5.8 \mathrm{~Hz}$, $4 \mathrm{H}, \mathrm{CH}_{2}-\mathrm{NH}$ ); 3.17 (s, 2H, $-\mathrm{CO}-\mathrm{CH}_{2}-\mathrm{CO}$ ).

${ }^{13}$ C-NMR $\left(\mathrm{d}_{6}-\mathrm{DMSO}, 100 \mathrm{MHz}, \mathrm{ppm}\right): 171.5 ; 167.5 ; 42.9 ; 42.7 ; 41.2$.

Diethyl 2,2'-[(1,3-dioxopropane-1,3-diyl)diimino]diacetate or diethyl malonyl-diglycinate (2).

Compound $1(8.00 \mathrm{~g}, 36.67 \mathrm{mmol})$ was dissolved in $150 \mathrm{~mL}$ of ethanol and $348.8 \mathrm{mg}$ (1.83 mmol, 5\% molar ratio) of $p$-toluenesulfonic acid monohydrate was added. The reaction mixture was heated under reflux for $90 \mathrm{~h}$ ). The solvents were then removed on a rotary evaporator to form solidifying oil. This product was purified using the extraction technique (DCM: $\mathrm{NaHCO}_{3}$ solution). The organic phase was dried using anhydrous $\mathrm{CaCl}_{2}$ and evaporated in vacuo to form a slightly yellowish oil. The final product was obtained with an $80 \%$ yield $(8.09 \mathrm{~g})$.

${ }^{1} \mathbf{H}$-NMR $\left(d_{6}-D M S O, 500 \mathrm{MHz}, \mathrm{ppm}\right): 8.44(\mathrm{t}, J=5.7 \mathrm{~Hz}, 2 \mathrm{H}, \mathrm{NH}) ; 4.09\left(\mathrm{~m}, 4 \mathrm{H}, \mathrm{CH}_{2}-\right.$ $\left.\mathrm{CH}_{3}\right) ; 3.85\left(\mathrm{~d}, J=5.7 \mathrm{~Hz}, 4 \mathrm{H}, \mathrm{CH}_{2}-\mathrm{NH}\right) ; 3.18\left(\mathrm{bs}, 2 \mathrm{H},-\mathrm{CO}-\mathrm{CH}_{2}-\mathrm{CO}\right) ; 1.18(\mathrm{t}, J=7 \mathrm{~Hz}$, $\left.6 \mathrm{H}, \mathrm{CH}_{3}\right)$.

${ }^{13}$ C-NMR $\left(d_{6}\right.$-DMSO, $\left.125 \mathrm{MHz}, \mathrm{ppm}\right): 170.1 ; 167.6 ; 61.0 ; 42.9 ; 42.5 ; 41.3 ; 14.4,14.3$ 


\section{Synthesis of diserinol malonate acetate (3)}

Diserinol malonate and its peracetylated version were synthesized on a large scale using a modified protocol (Serda et al. 2018). Briefly, 2-amino-1,3-propanediol (100 g, $1076 \mathrm{mmol}$ ) and dimethyl malonate $(57.4 \mathrm{~mL}, 500 \mathrm{mmol})$ were dissolved in dry isopropanol, heated with vigorous stirring at $50{ }^{\circ} \mathrm{C}$ for $30 \mathrm{~min}$ and then stirred at room temperature, under a nitrogen atmosphere for 14 days. After that time, the solid precipitate was filtered off and washed with cold isopropanol. After recrystallization from isopropyl alcohol, the white solid was obtained and dried under lyophilization (m.p. $132{ }^{\circ} \mathrm{C}$, yield $92 \%)$. Serinol malonate $(25.0 \mathrm{~g}, 99.9 \mathrm{mmol})$ was suspended in pyridine $(100 \mathrm{~mL}$, $1240 \mathrm{mmol})$ at $0{ }^{\circ} \mathrm{C}$, to which acetic anhydride $(150 \mathrm{~mL}, 1590 \mathrm{mmol})$ was added dropwise over the course of an hour. After reaching $25^{\circ} \mathrm{C}$, dissolution occurred and the solution was stirred continuously for $48 \mathrm{~h}$. At $0{ }^{\circ} \mathrm{C}$, methanol $(50 \mathrm{~mL}, 1225 \mathrm{mmol})$ was added to quench the remaining acetic anhydride and the solution was stirred for $1 \mathrm{~h}$, after which the solvents were removed in vacuo and the residue (yellow oil) was dissolved in dichloromethane and recrystallized for $12 \mathrm{~h}$ in hexane. The precipitate was collected as white crystals via filtration, washed with hexane and dried in vacuo (m.p. $91{ }^{\circ} \mathrm{C}$, lit. 91-92 ${ }^{\circ} \mathrm{C}$ (Clark et al. 1972)).

\section{[60]Fullerene hexakis adduct (6)}

The $\mathrm{C}_{60}$ (360 mg, $\left.0.500 \mathrm{~mol}\right)$ was added to a freshly distilled toluene $(400 \mathrm{~mL})$, mixed for 20 min using a magnetic stirrer and suspended using an ultrasonic bath. Then, $\mathrm{CBr}_{4}(248.7 \mathrm{mg}, 0.75 \mathrm{mmol})$ and malonate $2(137.1 \mathrm{mg}, 0.500 \mathrm{mmol})$, both of which were suspended in dichloromethane $(7 \mathrm{~mL})$, were added. Next, 1,8-diazabicyclo[5.4.0] undec-7-ene (DBU, $95.1 \mathrm{mg}, 0.625 \mathrm{mmol}$ ) in $5 \mathrm{~mL}$ of DCM was added and the reaction was allowed to proceed for $3 \mathrm{~h}$ at room temperature. The final product was isolated using the flash chromatography technique, (silica: Mallinckrodt, 75-250 $\mu \mathrm{m}$ particles, $150 \AA$ A pore size). The unreacted residue and impurities were removed with toluene and dichloromethane and then the product was eluted with $\mathrm{CH}_{2} \mathrm{Cl}_{2}: \mathrm{MeOH}$ 5:1 $(240 \mathrm{~mL})$ and $\mathrm{CH}_{2} \mathrm{Cl}_{2}: \mathrm{MeOH}$ 2:1 $(225 \mathrm{~mL})$ mixtures. The dark brown filtrate was evaporated in vacuo to form a brown solid (powder). This final product was obtained with a $64 \%$ yield (315 mg) and the mass was confirmed using MALDI-TOF (Additional file 1: Fig. S1). The obtained monoadduct $4(183 \mathrm{mg}, 0.184 \mathrm{mmol})$, diserinol malonate acetate $(771.1 \mathrm{mg}$, $1.843 \mathrm{mmol})$ and $\mathrm{CBr}_{4}(1222.3 \mathrm{mg}, 3.686 \mathrm{mmol})$ were dissolved in $20 \mathrm{~mL}$ of DCM; to which $170 \mathrm{~mL}$ of freshly distilled toluene was added and stirred for $5 \mathrm{~min}$. Next, 1,8-diazabicyclo[5.4.0] undec-7-ene (DBU, $337 \mathrm{mg}, 2.212 \mathrm{mmol}$ ) in dichloromethane (3 mL) was added slowly over the course of $4 \mathrm{~h}$ and the reaction was allowed to proceed with mixing at room temperature for $34 \mathrm{~h}$. Flash chromatography was used (silica: Mallinckrodt, 75-250 $\mu \mathrm{m}$ particles, $150 \AA$ A pore size) to isolate the hexakis product. The unreacted residue and some of the impurities were removed with toluene and dichloromethane and then the product was eluted with a $\mathrm{CH}_{2} \mathrm{Cl}_{2}: \mathrm{MeOH}$ 5:1 (360 mL) mixture. The brown filtrate was evaporated ( $100 \mathrm{~mL}$ flask) in vacuo to form a dark brown grease $(2.003 \mathrm{~g})$, which was hydrolysed in order to obtain unprotected derivative $\mathbf{6}$. For this purpose, the protected [60]fullerene derivative 5 (1.966 g) was dissolved in $20 \mathrm{~mL}$ of dry DCM and then sodium hydride $(200.0 \mathrm{mg}, 8.33 \mathrm{mmol})$ was carefully added in portions and stirred 
for $15 \mathrm{~min}$. Next, methanol was added $(8 \mathrm{~mL}$, in portions of $0.2-0.5 \mathrm{~mL})$ and during this period, intense bubbling was observed (at the bottom of the flask, however, unreacted so it remained). The flask was tightly closed and the reaction with mixing was allowed to proceed at room temperature for $60 \mathrm{~h}$. Then, $1.5 \mathrm{~mL}$ of methanol was added to the brown mixture in the flask; no bubbling was observed. The solvents were evaporated in vacuo to form a black solid (1.735 g). Next, a partially cleaved fullerene nanomaterial was placed in a $100-\mathrm{mL}$ flask and then 1,4-dioxane $(18 \mathrm{~mL})$ and concentrated hydrochloric acid ( $3 \mathrm{~mL}, 35 \%)$ were added (the black solid product immediately dissolved). The flask was tightly closed and the reaction mixture was allowed to proceed for further hydrolysis at room temperature for 7 days. The solvents were evaporated in vacuo to form a brown solid of compound $6(2.092 \mathrm{~g})$. The final product was purified by dialysis of an aqueous solution of fullerene 6 using cellulose membranes (molecular weight exclusion limit $1.0 \mathrm{kDa}$; Spectrum Labs, USA). The dialysis lasted 7 days, and the final fullerene nanomaterial $\mathbf{6}$ was concentrated, frozen and lyophilized. The final product was obtained as a brown solid with a $35 \%$ yield $(137.8 \mathrm{mg})$.

\section{$\mathrm{NanoC}_{60} \mathrm{GEM}$}

In a small vial, 1-ethyl-3-(3-dimethylaminopropyl)carbodiimide (EDCI, $6.60 \mathrm{mg}$, $0.034 \mathrm{mmol}$ ), $N$-hydroxysuccinimide (NHS, $3.96 \mathrm{mg}, 0.034 \mathrm{mmol}$ ) and fullerene 6 (30.0 mg, $0.0014 \mathrm{mmol}$ ) were dissolved in $2 \mathrm{~mL}$ of a MES buffer (10\% 2-( $N$-morpholino) ethanesulfonic acid in water, $\mathrm{pH}=4.5)$. After $5 \mathrm{~min}$ of stirring, the whole mixture was added (rinsing the vial twice with $0.5 \mathrm{~mL}$ of the MES buffer) into a reaction vessel $(10 \mathrm{~mL})$ containing gemcitabine $(\mathrm{GEM}, 10.32 \mathrm{mg}, 0.034 \mathrm{mmol})$. The [60]fullerene derivative 6 was dissolved instantly and the reaction vessel was placed on a magnetic stirrer at room temperature for $92 \mathrm{~h}$. Afterwards, the final product was purified by dialysis against an aqueous solution, using a cellulose membrane $(10 \mathrm{~mL}$, molecular weight exclusion limit $1.0 \mathrm{kDa}$; Spectrum Labs, USA). The dialysis lasted 10 days and the water was changed twice a day. Finally, the dialysate was concentrated, frozen and lyophilized. The final product was obtained as a brown solid with a $79 \%$ yield $(29.42 \mathrm{mg})$ and its purity was confirmed by HPLC (Additional file 1: Fig. S7).

\section{Time-resolved singlet oxygen detection}

Phosphate-buffered (pD 7.4, $10 \mathrm{mmol}$ ) $\mathrm{D}_{2} \mathrm{O}$ solutions of nano $\mathrm{C}_{60}$-GEM and TMPyP in a 1-cm-optical path quartz fluorescence cuvette (QA-1000; Hellma, Mullheim, Germany) was excited by light pulses that were generated by an integrated nanosecond DSS Nd:YAG laser system, equipped with a narrow bandwidth optical parametric oscillator (NT242-1k-SH/SFG; Ekspla, Vilnius, Lithuania). The laser system delivered pulses at a $1-\mathrm{kHz}$ repetition rate, with a pulse energy up to several hundred microjoules in the visible region, and up to several tens of microjoules in the UVA-UVB region. The [60] fullerene photosensitizers were photoexcited using a $427 \mathrm{~nm}$ wavelength. The absorbance of the samples was set to 0.27 in that wavelength. In order to adjust the photoexcitation energy in the experiments, a laser beam was attenuated with three pieces of wire mesh (light transmission $40 \%$ each). The quantum yield of singlet oxygen formation was calculated using 5,10,15,20-tetrakis(1-methyl-4-pyridinio)porphyrin tetra( $p$-toluenesulfonate) (TMPyP) as the reference compound $(\phi=0.75)$ (Snyder et al. 2006). 


\section{Electron paramagnetic resonance spin trapping studies}

EPR spin trapping was used with DMPO as the spin trap at a concentration of $100 \mathrm{mM}$. Samples containing $0.1 \mathrm{mg} / \mathrm{mL}^{\text {nanoC }} 60$ GEM in $80 \%$ DMSO were irradiated in EPR quartz flat cells in the resonant cavity with $402-$ to $508-\mathrm{nm}\left(24 \mathrm{~mW} / \mathrm{cm}^{2}\right)$ light, which was produced by a 300-W high-pressure compact arc xenon lamp (Cermax, PE300CE13FM/Module300W; PerkinElmer Optoelectronics, GmbH, Wiesbaden, Germany). The irradiation setup was equipped with a water filter, heat reflecting hot mirror, cut-off filter that blocked light below $390 \mathrm{~nm}$ and a blue additive dichroic filter 505FD64-25 (Andover Corporation, Salem, NH, USA).

\section{Cell lines and culture methods}

The human breast carcinoma; MCF-7 and human lung carcinoma epithelial-like A549 were obtained from the American Type Culture Collection (ATCC). The human pancreas adenocarcinoma AsPc-1 and pancreatic carcinoma of a ductal origin PANC-1 were obtained from Sigma-Aldrich. The murine pancreatic ductal adenocarcinoma; PAN02 was obtained from NCI-Frederick Cancer Research Facility and the normal human fibroblasts NHDF was obtained from PromoCell. The cell lines; MCF-7, A549, PANC-1 and NHDF were grown in Dulbecco's modified Eagle's medium (DMEM). The DMEM for MCF-7, A549 and PANC-1 were supplemented with 12\% heat-inactivated fetal bovine serum (Sigma) and for the NHDF with 15\% non-inactivated fetal bovine serum (Sigma). The AsPc-1 and PAN02 cell lines were cultured in a RPMI 1640 medium (Gibco, UK), which had been supplemented with $10 \%$ heat-inactivated fetal bovine serum (Sigma). All of the culture media were supplemented with the antibiotics penicillin/streptomycin (Gibco) $(1 \% \mathrm{v} / \mathrm{v})$. The cell lines were grown as monolayer cultures in $75 \mathrm{~cm}^{2}$ flasks (Nunc) under standard conditions at $37^{\circ} \mathrm{C}$ in a humidified atmosphere at $5 \% \mathrm{CO}_{2}$. All of the cell lines were tested for Mycoplasma contamination.

\section{Cytotoxicity studies}

The cells were seeded in 96-well plates (Nunc) at a density of $5 \times 10^{3}$ cells/well for the cancer cell lines and $4 \times 10^{3}$ cells/well for the normal cell line (NHDF) and incubated at $37{ }^{\circ} \mathrm{C}$ for $24 \mathrm{~h}$. An MTS assay (CellTiter $96^{\circledR}$ AQueous One Solution Cell Proliferation Assay from Promega) was performed after a $72 \mathrm{~h}$ incubation of the cells using nanoC ${ }_{60}$ GEM $(2-0.1 \mathrm{mg} / \mathrm{mL})$ and gemcitabine $(0.01-25 \mu \mathrm{M})$. The medium was then removed and $20 \mathrm{~mL}$ of a CellTiter $96^{\circledR} \mathrm{AQueous}$ One Solution-MTS (Promega) was added to each well (with $100 \mathrm{~mL}$ DMEM without phenol red) and incubated at least for $1 \mathrm{~h}$ at $37{ }^{\circ} \mathrm{C}$. The absorbance of the samples was measured at $490 \mathrm{~nm}$ using a multi-plate reader (Synergy 4, BioTek). The results which were expressed as a percentage of the control were calculated as the inhibitory concentration $\left(\mathrm{IC}_{50}\right)$ values using GraphPad Prism 7. Each experiment was repeated at least three times, each in triplicate.

\section{Cell cycle assay}

The PAN02 cells were seeded in $3 \mathrm{~cm}$ Petri dishes (Nunc) at a density of $1.5 \times 10^{5}$ cells/dish and incubated at $37{ }^{\circ} \mathrm{C}$ for $24 \mathrm{~h}$. Then, solutions of the nanoC ${ }_{60} \mathrm{GEM}$ (35 
and $17 \mu \mathrm{M})$ and gemcitabine $(1.5$ and $0.75 \mu \mathrm{M})$ were added. After a 48-h treatment, an assay was performed using a Muse Cell-Cycle Kit (Millipore) according to the manufacturer's instructions. Briefly, the cells were collected, washed with cold PBS and centrifuged at $300 \mathrm{~g}$. Next, the cells were fixed in ice-cold 70\% ethanol and stored at $-20{ }^{\circ} \mathrm{C}$ overnight. Afterwards, the cells were centrifuged and resuspended in 200 $\mu \mathrm{L}$ of a Muse ${ }^{\mathrm{TM}}$ Cell Cycle Reagent and incubated for $30 \mathrm{~min}$ at room temperature in the dark. After staining, the cells were processed for the cell cycle analysis using a Muse Cell Analyzer (Millipore). The experiments were performed at least three times, each in triplicate.

\section{Annexin $\mathrm{V}$ binding assay}

The PAN02 cells were seeded in 3-cm Petri dishes (Nunc) at a density of $1,5 \times 10^{5}$ cells/ dish and incubated at $37^{\circ} \mathrm{C}$ for $24 \mathrm{~h}$. Then, solutions of the nanoC ${ }_{60} \mathrm{GEM}(35$ and $17 \mu \mathrm{M})$ and gemcitabine $(1.5$ and $0.75 \mu \mathrm{M})$ were added. After $48 \mathrm{~h}$, an assay was performed using an Annexin V \& Dead Cell Kit (Millipore) according to the manufacturer's instructions. Briefly, both detached and adherent cells were collected and centrifuged at $500 \mathrm{~g}$ for $5 \mathrm{~min}$. Afterwards, the resuspended cells were incubated with $100 \mu \mathrm{L}$ of a Muse ${ }^{\mathrm{TM}}$ Annexin V \& Dead Cell Reagent for $20 \mathrm{~min}$ at room temperature in the dark. After staining, the events for live, early and late apoptotic cells were counted using a Muse Cell Analyzer (Millipore). The experiments were performed at least three times, each in triplicate.

\section{Photodynamic therapy on the PAN02 cell line}

The PAN02 line cells were plated in 24-well plates at density of 35,000/well. Twenty-four hours after plating, the cells were incubated with high-glucose DMEM that contained nano $_{60}$ GEM at different concentrations. Feeding was repeated two more times, at $24-\mathrm{h}$ intervals. The day after the final feeding the cells were washed twice with PBS that contained calcium and magnesium ions, then irradiated for 15 min using a blue led light $\left(440 \mathrm{~nm}\right.$ ) at a fluence rate $20 \mathrm{~mW} / \mathrm{cm}^{2}$. Dark control cells were kept in the same conditions except light exposure. After irradiation, the cells were provided with DMEM with $10 \%$ FBS. The cytotoxic effect of the photodynamic treatment was quantified $24 \mathrm{~h}$ after irradiation, using a MTT assay for the mitochondrial redox function. The MTT solution in DMEM with $10 \%$ FBS was added to the treated and control culture wells (final concentration of $0.5 \mathrm{mg} / \mathrm{mL}$ ). After incubation for $30 \mathrm{~min}$ at $37^{\circ} \mathrm{C}$, the culture medium was removed and the remaining blue precipitate was solubilized in DMSO, followed by reading the absorbance at $560 \mathrm{~nm}$ in a plate reader (GENios Plus, Tecan Austria GmbH). The results are reported as the percentage of the paired untreated controls. The experiments were repeated a minimum of three times.

\section{Statistical analysis}

The results are expressed as the mean \pm standard deviation (SD) from at least three independent experiments. A statistical analysis was performed using the one-way ANOVA with a Bonferroni post hoc test. A $p$ value of 0.05 or less was considered to be statistically significant. GraphPad Prism v.7.0 software (GraphPad Software, USA) was used for the analysis (Fig. 1). 


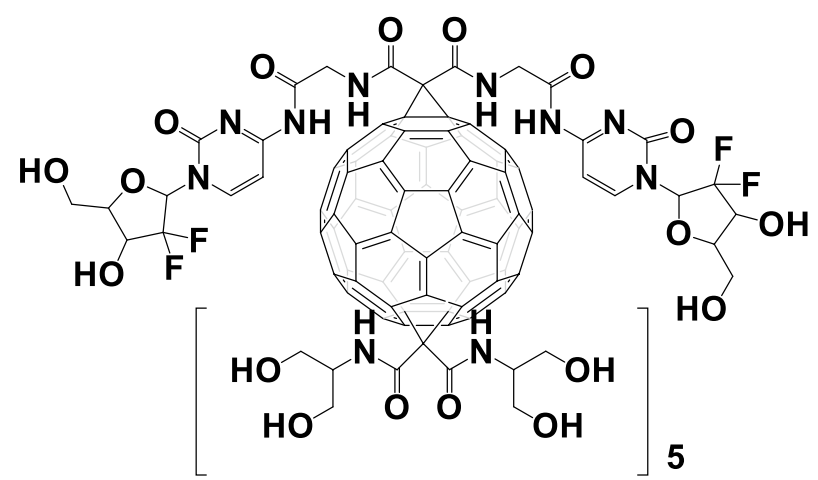

Fig. 1 Chemical structure of nano ${ }_{60}-\mathrm{GEM}$

\section{Results and discussion}

\section{Synthetic protocol and characterization of nano $\mathrm{C}_{60} \mathrm{GEM}$}

The synthetic protocol for obtaining nanoC ${ }_{60}$ GEM is shown in Scheme 1. During our design step, we decided to use a glycine derivative of malonic acid $\mathbf{1}$ as the substrate for the Bingel-Hirsch reaction. We expected that the carboxylic groups, which are present in that compound would be much more reactive toward the aromatic amines (i.e., the cytosine fragment in the gemcitabine) in contrast to the malonic acid derivatives, which are closely connected the [60]fullerene scaffold, based on literature findings (Wang et al. 2015). The desired [60]fullerene monoadduct 4 was created in a high yield by in situ generation of $\alpha$-brominated malonate 2 in the presence of $\mathrm{CBr}_{4} / \mathrm{DBU}$ at room temperature in a time-controlled reaction, where monoadducts were formed up to $3 \mathrm{~h}$. However, after that time, bis- and tris-adducts formed, which made the purification process more complicated. The structure of the monoadduct 4 was confirmed using MALDI-TOF spectrometry with a characteristic peak at $992 \mathrm{Da}$ and no presence of the bis- or trisadducts (Additional file 1: Fig. S1). The second Bingel-Hirsh reaction was performed using diserinol malonate acetate (malonate 3 ) in order to ensure a high degree of water solubility and the desired hexakis adduct with $T_{h}$ symmetry was created (compound $\mathbf{5}$ ) in a good yield. The deprotection of fullerene $\mathbf{5}$ was performed in a two-step procedure, which involved hydrogenolysis with sodium hydride first and then the final hydrolysis with 1,4-dioxane with concentrated $\mathrm{HCl}$ added. The molecular peak of the [60]fullerene derivative 6 is shown in Additional file 1: Fig. S2 with the characteristic mass of $2195 \mathrm{Da}$ $\left[\mathrm{M}+\mathrm{H}_{2} \mathrm{O}+\mathrm{H}\right]^{+}$and no signals from the pentakis isomer. The final step of the conjugation with GEM was performed using the water-soluble carbodiimide EDCI/NHS system in a solution of a MES buffer. The ESI spectrometry confirmed the formation of the desired nano $\mathrm{C}_{60}$ GEM (Additional file 1: Fig. S3) which had a characteristic signal of the molecular peak at $2690 \mathrm{Da}[\mathrm{M}+\mathrm{Na}]^{+}$, which represented the [60]fullerene derivative 6 that had been conjugated to two molecules of gemcitabine via an amide bond. Interestingly, a fragmentation pattern, in which one serinol group left the nano ${ }_{60} \mathrm{GEM}$ (characteristic at $2578 \mathrm{Da}$, Additional file 1: Fig. S3), was observed.

The UV-VIS spectrum of nanoC ${ }_{60} \mathrm{GEM}$ is characteristic for the water-soluble fullerenes that have a high absorbance only in the UV and blue regions of a spectrum (max absorbance was observed at $220 \mathrm{~nm}$ ). Moreover, we found that nanoC ${ }_{60} \mathrm{GEM}$ tends to form monodisperse aggregates around $120 \mathrm{~nm}$ as was confirmed by DLS (Additional 


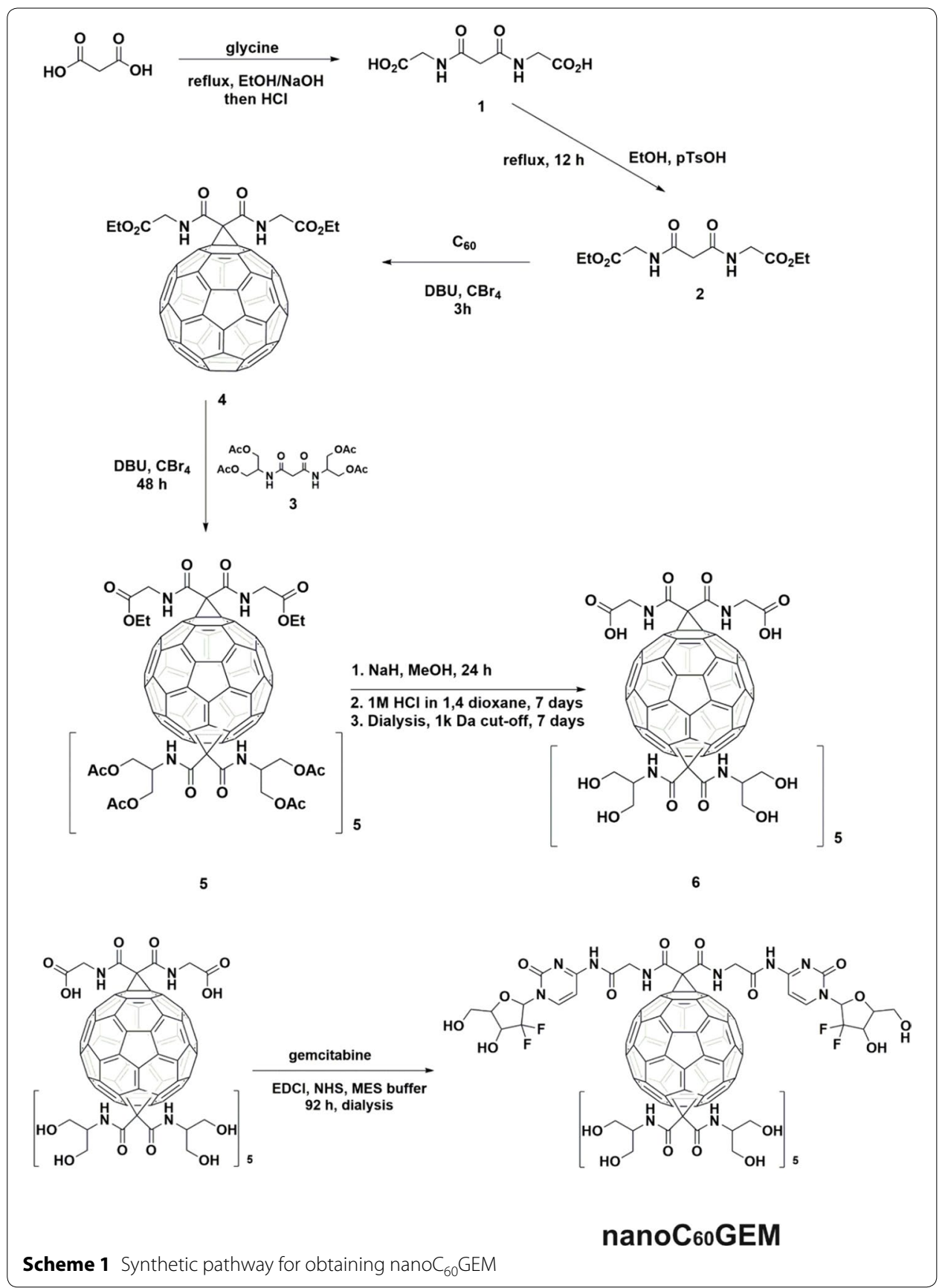

file 1: Fig. S4), and which may be disintegrated into smaller individual fullerenes inside the cell (Lapin et al. 2017b). The zeta potential measurements of our gemcitabine nanoconjugate (Additional file 1: Fig. S5) also indicated a surface charge of $-25 \mathrm{mV}$, thus confirming a relatively good degree of stability.

The infrared spectrum of the nanoC ${ }_{60}$ GEM system was divided into two spectral regions: (1) $2700-3800 \mathrm{~cm}^{-1}$ and (2) $700-1850 \mathrm{~cm}^{-1}$ (Fig. 2). The high wavenumber region is characterized by the presence of a broadened band that is centered at $3364 \mathrm{~cm}^{-1}$, which corresponded to the overlapping signal that had originated from the 

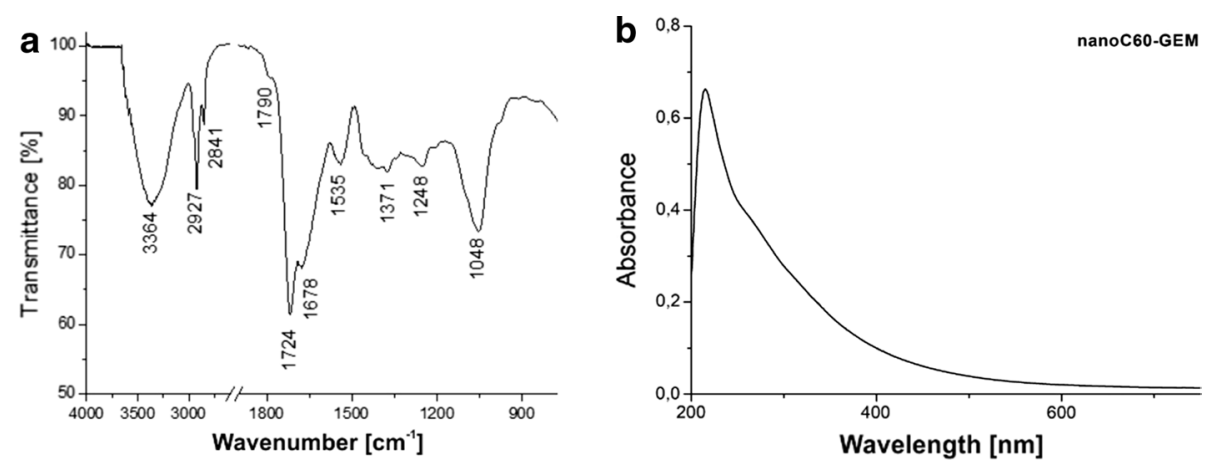

Fig. 2 a Infrared spectrum of nanoconjugate measured in the $700-4000 \mathrm{~cm}^{-1}$ range. $\mathbf{b}$ UV-VIS spectrum of nano $_{60} \mathrm{GEM}$ recorded in ultrapure water $(c=0.01 \mathrm{mg} / \mathrm{mL})$

hydroxyl (Motoyama and Jarboe 1966) and the secondary amide vibration (Lumley Jones 1963). The observable band shift toward a lower wavenumber, especially in relation to the hydroxyl group, may have resulted from the formation of an inter- or intramolecular hydrogen bonding scheme. In turn, the low-wavenumber bands with their maxima centered at 2927 and $2841 \mathrm{~cm}^{-1}$ may have originated from the asymmetric and symmetric stretching mode of the methylene groups that overlapped with the stretching vibration of the $\mathrm{CH}$ moieties.

The fingerprint (1) region, especially at high wavenumbers with a maxima located at 1790,1724 and $1678 \mathrm{~cm}^{-1}$, is determined by the carbonyl stretching modes due to primary amides (Craig and Evans 1965). The deformational mode of the secondary amide could have corresponded to the band at $1535 \mathrm{~cm}^{-1}$. In addition, this band has a combination character with vibration originated from the medium-strong vibration within the furan (Katritzky and Lagowski 1959) as well as the $\mathrm{C}=\mathrm{C}$ and $\mathrm{C}=\mathrm{N}$ ring stretching vibrations within the pyrimidin-2-one (Billes et al. 1998). The other low-intense bands with their maxima at 1371 and $1248 \mathrm{~cm}^{-1}$ were mainly linked to the deformational modes of the methylene groups that were located within the aliphatic chain or the furan and pyrimidin-2-one rings. In turn, the interpretation of the band at $1048 \mathrm{~cm}^{-1}$ was unambiguous because of the overlapping character of the various modes that may be activated at this wavenumber such as a $\mathrm{C}=\mathrm{C}-\mathrm{H}$ deformation within the aliphatic moieties or within the furan and pyrimidin-2-one, the $\mathrm{CN}$ of a secondary amine or asymmetric and symmetric vibration of the CF. In turn, the deformational mode of the CF could have been expected at $726 \mathrm{~cm}^{-1}$. Finally, one can summarize that the band arrangement indicated on the presence of the hydroxyl, secondary amine, and fluorine substituents, which confirmed that the synthesis had been performed successfully.

The chemical states of the elements that were present on a sample surface were analyzed using XPS. The change in the binding energy was related to changes in the chemical bonding with the surrounding elements. An analysis of the carbon chemical states was performed to analyze the $\mathrm{C} 1 \mathrm{~s}$ core level. A resolved line, see Fig. 3a, indicates the presence of several different chemical states of the carbon. The state with the lowest binding energy of $282.84 \mathrm{eV}$ was associated with the presence of an impurity of an $\mathrm{SiC}$ origin. The amount of this state was relatively low about $4.19 \%$ of the entire amount of carbon (see Additional file 1: Table S1). The highest peak, which 

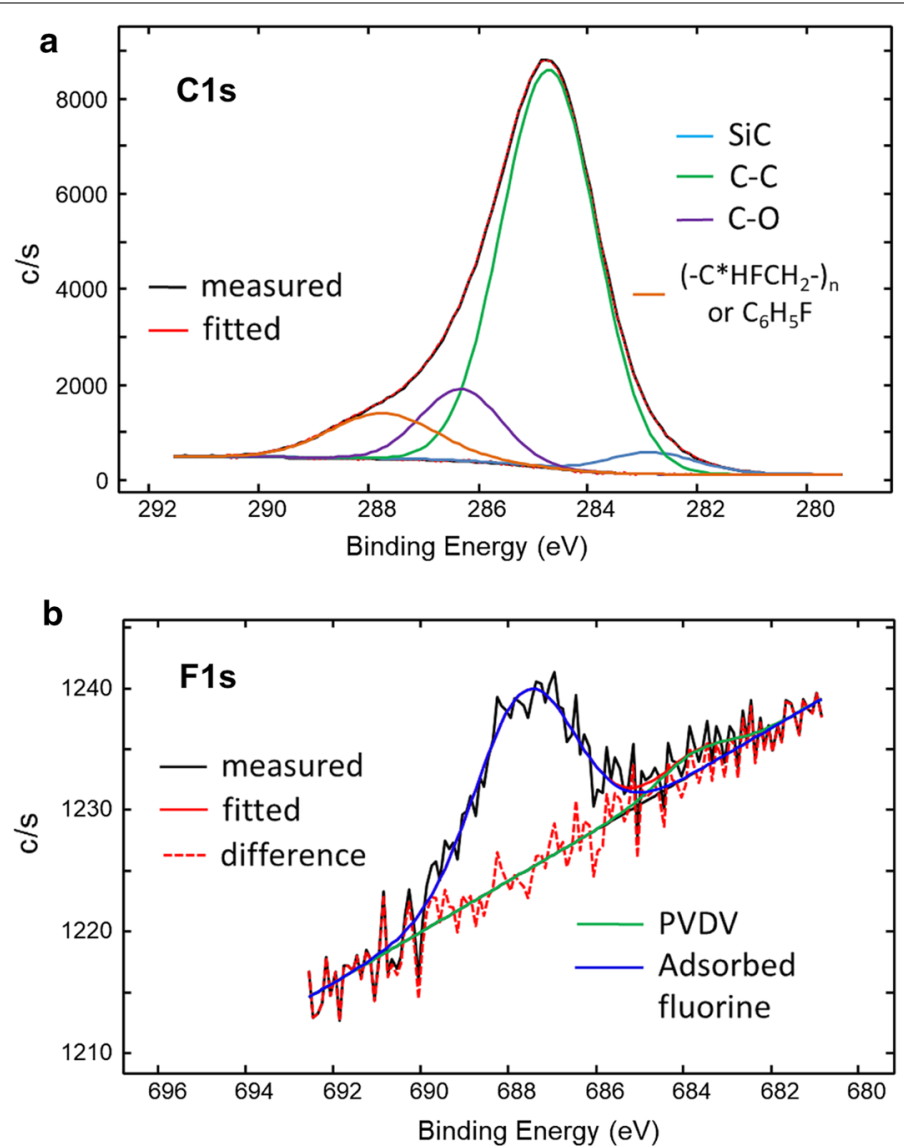

Fig. 3 The XPS high-resolution photoemission lines of nano $\mathrm{C}_{60}-\mathrm{GEM}$ : a carbon $\mathrm{C} 1 \mathrm{~s}$, and $\mathbf{b}$ fluorine $\mathrm{F} 1 \mathrm{~s}$

was located at $284.71 \mathrm{eV}$, indicates the presence of $\mathrm{C}-\mathrm{C}$ and $\mathrm{C}-\mathrm{H}$ type bonds (Watts 1993). The peak centered at $286.33 \mathrm{eV}$ could be assigned to the $\mathrm{C}-\mathrm{O}$ and $\mathrm{C}-\mathrm{N}$ bonds and has been the case for other fullerene derivatives (Yu et al. 2012), whereas the peak at $287.74 \mathrm{eV}$ corresponds to the states that have been observed in poly(vinyl fluoride) (Clark et al. 1973) or fluorobenzene (Clark et al. 1972) compounds. Fluorine analysis was difficult, mainly due to the quality of the spectrum, which resulted from the small amount of this element in the sample. Calculations of the atomic concentration indicated about 0.06 atomic percent of $\mathrm{F}$ on the sample surface, which is generally the detection limit of the XPS technique.

Nevertheless the fluorine 1s photoemission line had (see Fig. 3b) a peak that was located at $687.63 \mathrm{eV}$, and similar values were observed for graphite fluorides for which the peaks located in the range of $687-689 \mathrm{eV}$ were assigned to the adsorbed fluorine (Palchan et al. 1989). The weakly developed peak at $687.63 \mathrm{eV}$ may be associated with polyvinylidene fluoride (PVDF); however, as this state represents only $7 \%$ of all of the fluorine, which is itself a trace element, the analysis could not be precise. An analysis of oxygen confirmed what had been observed in the $\mathrm{C} 1 \mathrm{~s} \mathrm{C}-\mathrm{O}$ bonds. For nitrogen, the N1s line indicated the presence of two chemical states, one weakly developed at $397.57 \mathrm{eV}$, which was related to the $\mathrm{Si}_{3} \mathrm{~N}_{4}$ compound and the second of high intensity 
at $399.78 \mathrm{eV}$, which was related to the bonds that present in nylon. In the case of silicone, two chemical states were also present, one was centered at $100.33 \mathrm{eV}$ and was related to $\mathrm{SiC}$ and the second at $102.02 \mathrm{eV}$, which was related to $\mathrm{Si}_{3} \mathrm{~N}_{4}$. Additionally, a small amount of bromine was observed and was associated with AgBr. Taking into account the atomic concentrations, which were calculated from the XPS measurements, in which the amount of carbon was approximately 79.39 at.\%, oxygen 15.36 at.\%, nitrogen 3.89 at.\%, fluorine 0.06 at.\%, silicone 1.14 at.\%, and bromine 0.15 at.\%, both the $\mathrm{Si}$ and $\mathrm{Br}$ can be treated as trace elements that appeared due to synthetic impurities or sample preparation.

\section{Biophysical characterization of nano ${ }_{60} \mathrm{GEM}$}

The water-soluble [60]fullerene nanomaterials are well-known for their ability to produce different types of reactive oxygen species when irradiated by blue light (Mroz et al. 2007).

Based on previous literature studies, in polar solvents, in particular those containing donor electrons such as NADH, the irradiation of fullerenes leads to the generation of reduced oxygen species, such as superoxide anion radical $\left(\mathrm{O}_{2}^{*-}\right)$ and hydroxyl radical $(\mathrm{OH} \bullet)$. In non-polar solvents such as benzene, the process of singlet oxygen $\left({ }^{1} \mathrm{O}_{2}\right)$ is primarily formed (Yamakoshi et al. 2003). UV light has a very low ability to penetrate through tissue and can cause a non-specific effect in any cells it hits. In our study, we used blue LED light, which has a slightly better tissue penetration that does not cause any damage to cells that have no photosensitizer. The photoreactivity of the analyzed fullerene nanoparticles was determined by measuring their ability to generate, after irradiation with blue LED light, singlet oxygen and superoxide anion, which may have oxidizing effects on several cellular targets, especially under conditions with a low-oxygen concentration. In this study, we carried out singlet oxygen photogeneration studies of nano $\mathrm{C}_{60} \mathrm{GEM}$ using a cationic porphyrin (TMPyP) as the reference photosensitizer.

The calculated quantum efficiency of ${ }^{1} \mathrm{O}_{2}$ formation for our water-soluble [60]fullerene derivative, which had been irradiated by blue LED light was around 0.05 . Although the efficacy of singlet oxygen formation for pristine fullerene is almost at unity (at $532 \mathrm{~nm}$ ), chemical modifications can decrease their efficacy (Arbogast et al. 1991). Earlier studies with Bingel-Hirsch products confirmed the observation that monoadducts as well as aminofullerenes produce singlet oxygen more effectively than hexakis adducts (as nanoC $_{60} \mathrm{GEM}$ ) (Hamblin 2018). More importantly, we discovered that in the presence of bovine serum albumin $(100 \mathrm{mM})$ this process is reduced, suggesting a close interaction between fullerene and the formation of the protein corona (Fig. 4c).

We also measured superoxide photogeneration using the EPR spin-trapping method with DMPO as the spin trap. While nano $\mathrm{C}_{60} \mathrm{GEM}$ alone showed a negligible signal of trapped adducts, the presence of electron donor (NADH) increased the signal by an order of magnitude (Fig. 4b), thus showing that in favorable conditions, the electron transfer route may also contribute to a phototoxic effect. Spin trapping was performed in $80 \%$ DMSO, which made any measurements in the presence of BSA impossible as it would have destroyed the protein structure. Although the photoreactivity of our novel fullerene nanomaterial is not very high, its localization within cancer cells could make it more phototoxic if it is localized, for example, in the nucleus (Serda et al. 2018). 

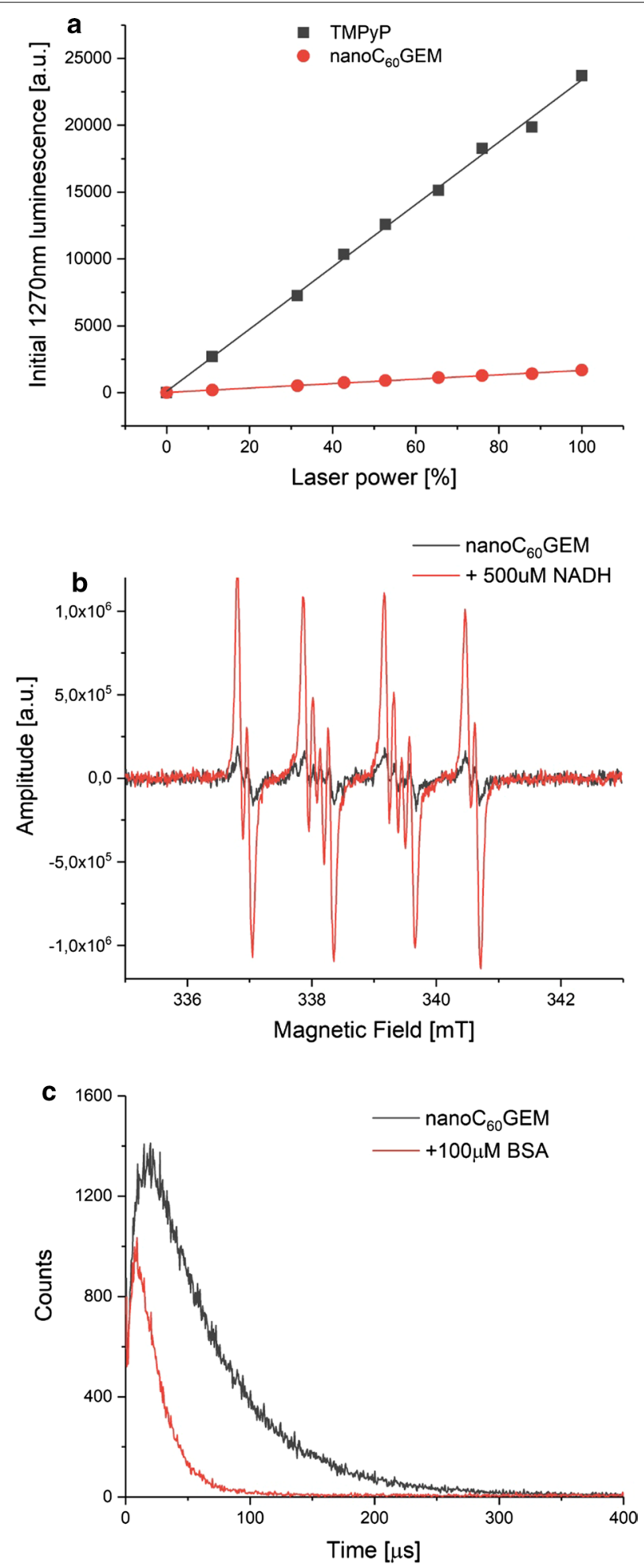

Fig. 4 Photoreactivity of nano ${ }_{60} G E M$. a Quantum yield of singlet oxygen generation after irradiation by blue LED light by nano $C_{60}$ GEM with TMPyP used as the reference photosensitizer; $\boldsymbol{b}$ spin adduct signal (DMPO-OOH) that was formed in the absence and presence of an electron donor (0.5 mM NADH) after blue LED light irradiation; c $1270 \mathrm{~nm}$ luminescence observed in the absence and presence (100 $\mu \mathrm{M}$ ) of bovine serum albumin 


\section{Biology}

\section{Cytotoxicity}

We performed cytotoxicity screening using several cancer cell lines of different origins including normal human fibroblasts. During the biological studies, we decided to study pancreatic, breast and lung cancers because of the clinical use of GEM for the aforementioned neoplasms (Xie et al. 2018; Watanabe et al. 2019). The calculated $\mathrm{IC}_{50}$ values are presented in Table 1.

We observed a noticeable cytotoxicity for two cell lines, MCF-7 and PAN02, for which we calculated the $\mathrm{IC}_{50}$ parameters to be $2.07 \pm 0.64$ and $7.35 \pm 1.13 \mu \mathrm{M}$, respectively. Compared to gemcitabine alone, the cytotoxic effect was reduced. A possible explanation of this phenomenon may be the ineffective transport of nanoC ${ }_{60}$ GEM into the nucleus. Gemcitabine is a deoxycytidine analog with two additional fluoride atoms and as nucleoside derivative, it is transported throughout human nucleoside transporters (hNTs) (Mackey et al. 1998).

We hypothesized that after GEM was conjugated with [60]fullerene, this type of transport would be unavailable. Additionally, GEM is incorporated into the C60 structure by the formation of an amide bond which, for steric hindrance, is probably difficult to access through the cellular enzymes such as proteases. Despite its higher activity toward the MCF-7 cell line, we selected the PAN02 cell line for the further studies because we also wanted to perform in vivo studies.

\section{Cell cycle}

In order to evaluate the mechanism of action of nanoC ${ }_{60} \mathrm{GEM}$, we performed a flow cytometry measurement. As is presented in Fig. 5, after $48 \mathrm{~h}$ of the incubation with nanoC ${ }_{60}$ GEM and gemcitabine, we observed a decrease in the faction of cells in the G0/ G1 phase (compared to the control). However, there was an increase in the number of cells in the $\mathrm{S}$ phase in all of the cases that were examined regardless of the concentration. This increase indicated an inhibition of the cell cycle in the $\mathrm{S}$ phase. This is consistent with Huang's studies for gemcitabine (Huang et al. 1991), which indicates that it inhibits DNA synthesis. After its uptake into a cell, gemcitabine is metabolized into an active triphosphate form. Thereafter, this form is embedded in the DNA chain, thereby preventing its elongation.

\section{Cell death}

In order to determinate the type of the cell death, we also used flow cytometry. In this experiment, after $48 \mathrm{~h}$ of incubation with nano $\mathrm{C}_{60} \mathrm{GEM}$ and gemcitabine, we measured the green signal that was derived from apoptotic cells. As is presented in Fig. 6, the

Table 1 Antiproliferative activity of the studied compounds

\begin{tabular}{lllllrl}
\hline Compound & \multicolumn{1}{l}{$\mathrm{IC}_{\mathbf{5 0}}[\boldsymbol{\mu M}]$} & & & & \\
\cline { 2 - 7 } & MCF-7 & AsPc-1 & PAN02 & PANC-1 & A549 & NHDF \\
\hline NanoC $_{60}$ GEM & $2.07 \pm 0.64$ & $>375$ & $7.35 \pm 1.13$ & $>375$ & $>375$ & $>375$ \\
Gemcitabine & $0.044 \pm 0.008$ & $0.207 \pm 0.046$ & $0.027 \pm 0.003$ & $21.95 \pm 3.99$ & $>25$ & $>25$ \\
\hline
\end{tabular}

The $\mathrm{IC}_{50}$ parameters were calculated using GraphPad Prism 7 


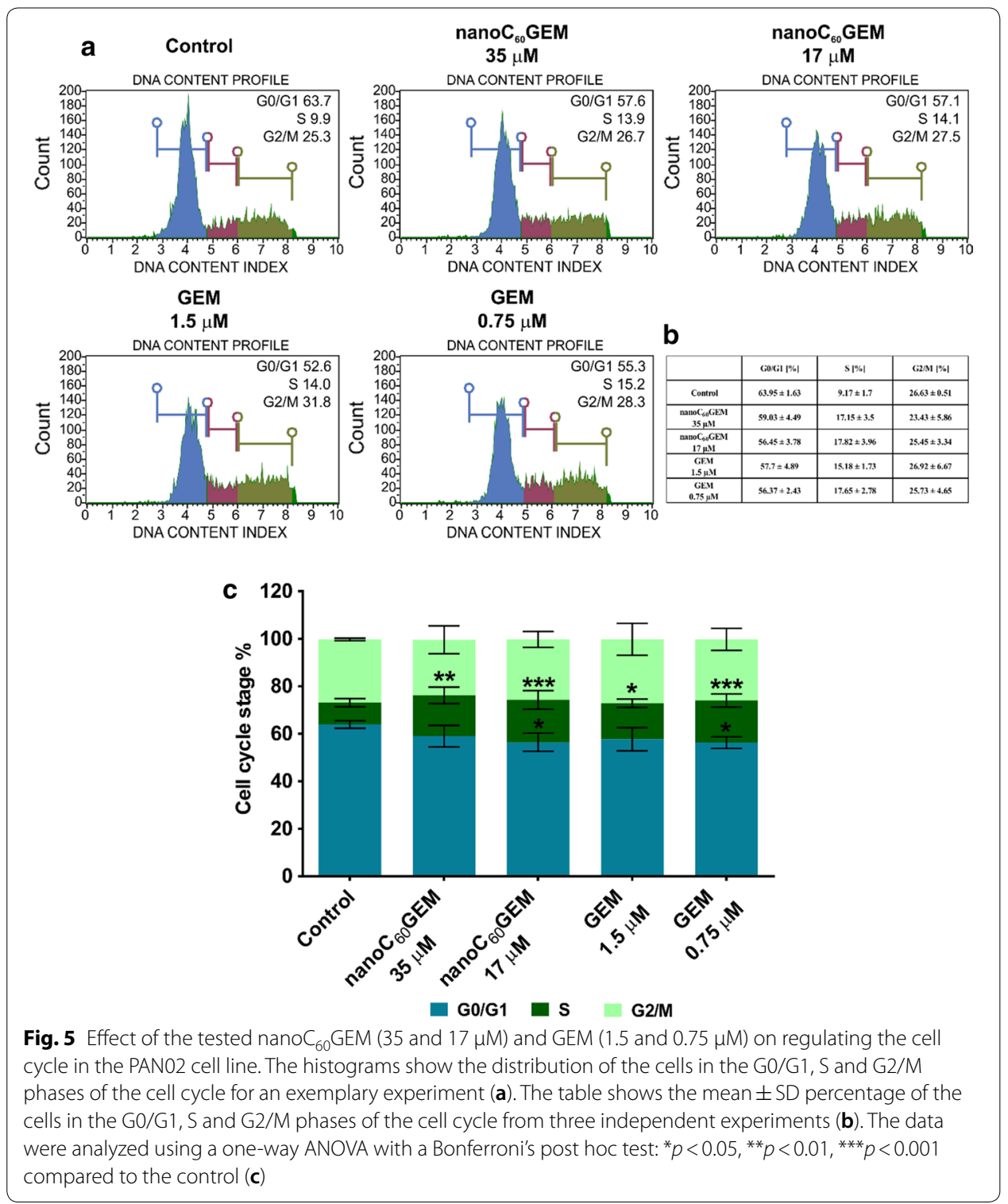

biggest fraction of the apoptotic cell was detected for gemcitabine (44\% compared to the control). There was no big difference between the two concentrations of GEM ( 0.75 and $1.5 \mu \mathrm{M})$ that were tested. However, for nano $\mathrm{C}_{60} \mathrm{GEM}$, we also registered a comparable population of apoptotic cells ( $38.6 \%$ for $35 \mu \mathrm{M}$ of nanoC $\left.{ }_{60} \mathrm{GEM}\right)$. These results are promising from the perspective of further studies.

\section{Phototoxicity studies}

According to research reports, [60]fullerene derivatives have a great potential to be used as photosensitizers in photodynamic therapy. In order to evaluate this hypothesis, we performed experiments in which the cells were incubated with nano $\mathrm{C}_{60} \mathrm{GEM}$ for 3 days to cause the cellular nucleases to cleave GEM from the nanoconjugate, after which the cells were irradiated with blue LED light. After the 

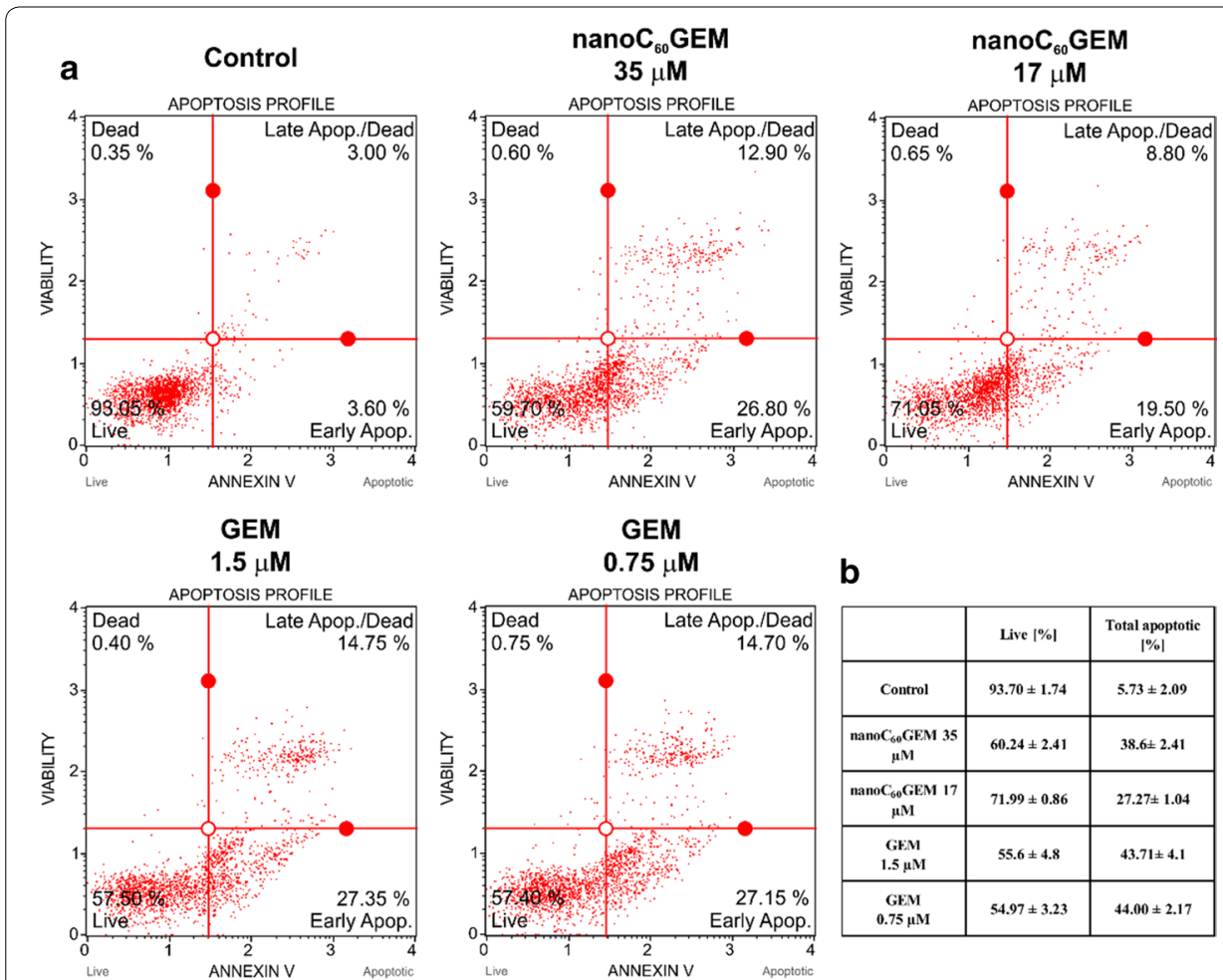

GEM

$0.75 \mu \mathrm{M}$

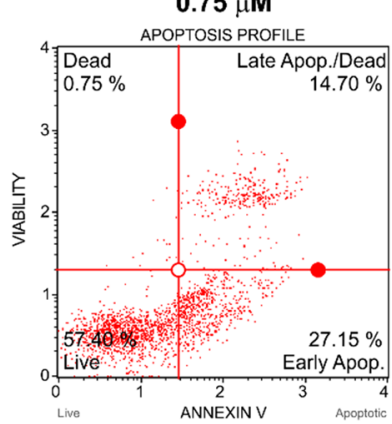

b

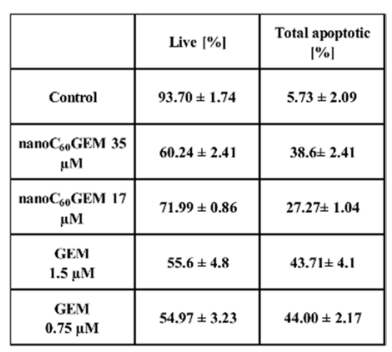

C

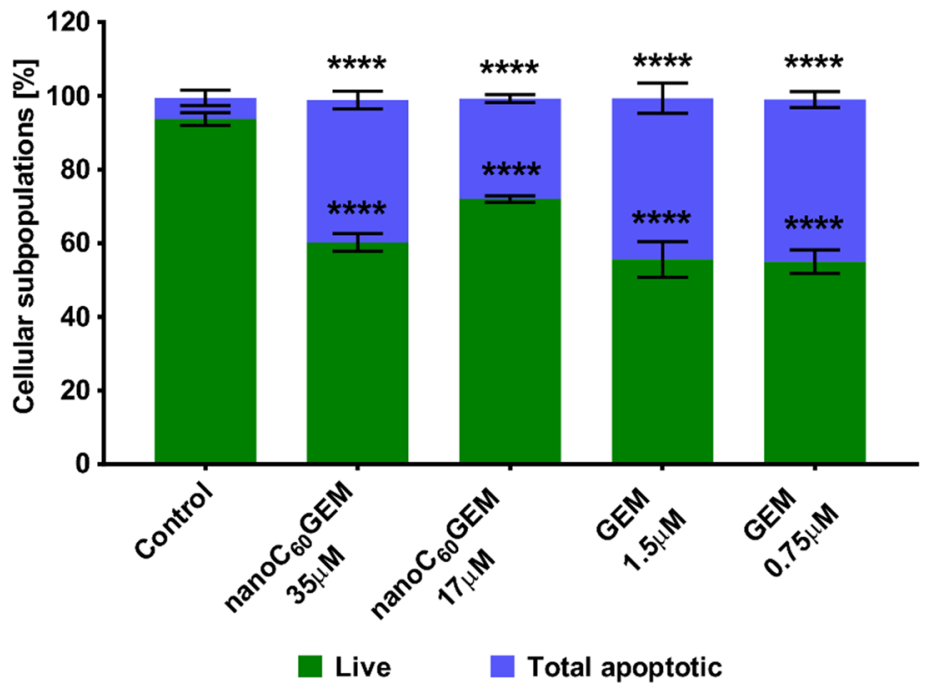

Fig. 6 Evaluation of the induction of apoptosis in the PAN02 cell line after a 48-h treatment with nano ${ }_{60} \mathrm{GEM}(35$ and $17 \mu \mathrm{M})$ and GEM $(1.5$ and $0.75 \mu \mathrm{M})$. The histograms show the percentage of early and late apoptosis for one of the experiments (a). The table shows the mean \pm SD percentage of the live, early and late apoptotic cells from three independent experiments $(\mathbf{b})$. The data were analyzed using one-way ANOVA with a Bonferroni's post hoc test: ${ }^{*} p<0.05,{ }^{* *} p<0.01,{ }^{* * *} p<0.001$ compared to the control (c)

irradiation a cell viability assay was performed $(24 \mathrm{~h}, \mathrm{MTT})$. The selection of the correct wavelength $(440 \mathrm{~nm})$ to be used was dictated by the absorption properties of the studied nanomaterial (Fig. 2b), in order to avoid UV part of the spectrum that could cause unspecific effects. As is depicted in Additional file 1: Fig. S4, the tested 
compound did not generate a significant level of the singlet oxygen and superoxide anion. Addition of an electron donor increased the superoxide production manyfold (Fig. 4b), but such favorable conditions are difficult to find in a cellular environment. Therefore, we conducted the experiments by adding BSA (Fig. 4c), which confirmed the interaction of the fullerene nanomaterial and the formation of the protein corona. Our results show that the interaction with conducts serum protein leads to a decrease in the observable signal of singlet oxygen, which may be caused by a decreased yield of the generation or by an increased quenching of the singlet oxygen by bounded proteins. To explore this issue in depth, we performed in vitro studies using a medium that contained FBS. The results, which are presented in Fig. 7, confirmed the non-toxic properties of the low concentrations of irradiated nano $C_{60} \mathrm{GEM}$, which reduced the chances of using this type of fullerene nanomaterial as a photosensitizer. Although the PAN02 cell line phototoxicity response was disappointing, we plan to study the effects of nanoC ${ }_{60} \mathrm{GEM}$ on different cancer cell lines and 3D-spheroids.

\section{Conclusions}

The developed synthetic protocol was able to produce a highly water-soluble [60]fullerene nanoconjugate with gemcitabine in good yield. The physio-chemical characteristics of the fullerene nanomaterial confirms that two gemcitabine units are attached to the [60]fullerene scaffold via formation of amide bonds. The nano $\mathrm{C}_{60}$ GEM cytotoxicity effect was dependent on its concentration in PAN02 cells, but its phototoxic effects were mild, partly due to the formation of the protein corona on the surface of the [60]fullerene scaffold as well as the low quantum yields of the singlet oxygen generation. Further biological studies using 3D-spheroids as well as murine models should be used in order to evaluate the efficacy of a therapy using nanoC ${ }_{60}$ GEM.

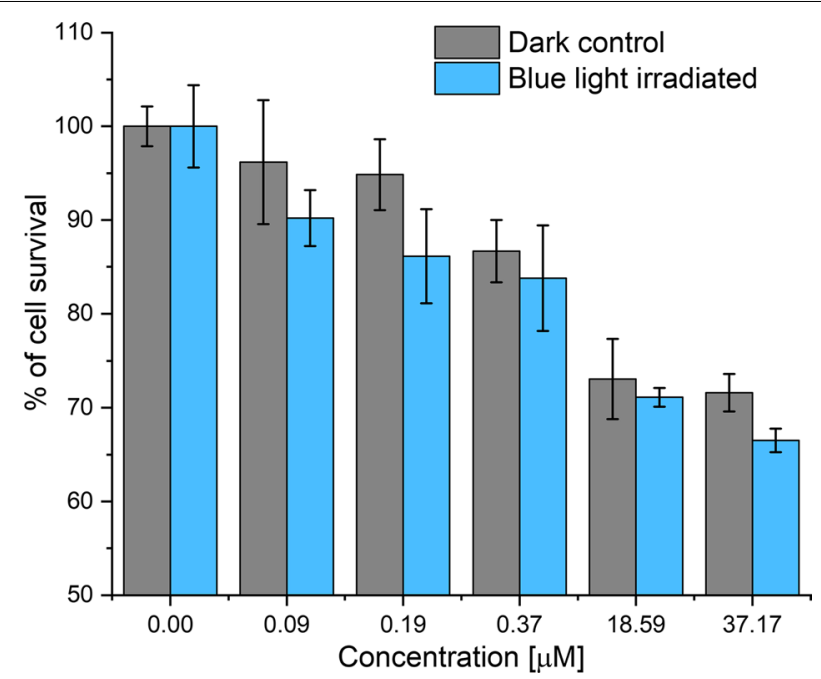

Fig. 7 Phototoxicity of nano ${ }_{60}$ GEM performed for the PANO2 cancer cell line 


\section{Supplementary information}

Supplementary information accompanies this paper at https://doi.org/10.1186/s12645-020-00058-4.

Additional file 1. The physico-chemical characteristics of nanocC ${ }_{60} \mathrm{GEM}$.

\section{Abbreviations}

ATCC: American Type Culture Collection; BSA: Bovine serum albumin; DLS: Dynamic light scattering; DMEM: Dulbecco's modified Eagle medium; DBU: 1,8-Diaza-bicyclo[5.4.0] undec-7-ene; DCM: Dichloromethane; DMPO: 5,5-Dimethyl1-pyrroline N-oxide; DMSO: Dimethylsulfoxide; DNA: Deoxyribonucleic acid; EDCl: 1-Ethyl-3-(3-dimethylamino propyl) carbodiimide; EPR: Enhanced permeability and retention effect; EPR: Electron paramagnetic resonance; FBS: Fetal bovine

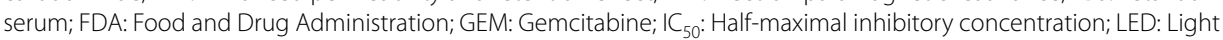
emitting diode; MALDI: Matrix-assisted laser desorption/ionization; HM: Micromolar; MS: Mass spectrometry; MTT: (3[4,5-Dimethyl-thiazol-2-yl]-2,5-diphenyltetrazolium bromide); NADH: Nicotinamide adenine dinucleotide reduced form; nano ${ }_{60} \mathrm{GEM}:[60]$ Fullerene derivative nanoconjugate with gemcitabine; NHS: $\mathrm{N}$-Hydroxysuccinimide; PBS: Phosphatebuffered saline; PVDF: Polyvinylidene fluoride; RPMI: Roswell Park Memorial Institute; S phase: Synthesis phase; TMPyP: 5,10,15,20-Tetrakis(1-methyl-4-pyridinio)porphyrin tetra( $p$-toluenesulfonate); XPS: X-ray photoelectron spectroscopy.

\section{Acknowledgements}

Not applicable.

\section{Authors' contributions}

Conception and design: MS, GSZ and AMW. Acquisition of data: PN, RG, GS, MS, KB, MD, and MS. Analysis and interpretation of the data: MS, GSZ and AMW. Manuscript preparation: MS, GSZ, AMW, JP and RM wrote the manuscript. All authors read and approved the final manuscript.

\section{Funding}

Dr. Maciej Serda thanks the National Science Center (Poland) for its support (Grant SONATA UMO-2016/23/D/

NZ7/00912). Dr. Mateusz Dulski is thankful for the financial support from the National Science Center based on decision 2017/26/D/ST8/01117.

\section{Availability of data and materials}

The datasets used and/or analyzed during the current study are available from the corresponding author on reasonable request.

\section{Ethics approval and consent to participate}

Not applicable.

\section{Consent for publication}

Not applicable.

\section{Competing interests}

We confirm that we have given due consideration to the protection of intellectual property associated with this work and that there are no impediments to publication, including the timing of publication, with respect to intellectual property. The authors declare that they have no competing interests.

\section{Author details}

${ }^{1}$ Institute of Chemistry, University of Silesia in Katowice, Katowice, Poland. ${ }^{2}$ Institute of Physics and Silesian Center for Education and Interdisciplinary Research, University of Silesia in Katowice, Katowice, Poland. ${ }^{3}$ Faculty of Biochemistry, Biophysics and Biotechnology, Jagiellonian University, Kraków, Poland. ${ }^{4}$ Institute of Materials Engineering and Silesian Center for Education and Interdisciplinary Research, University of Silesia in Katowice, Katowice, Poland.

Received: 5 October 2019 Accepted: 3 February 2020

Published online: 18 February 2020

\section{References}

Arbogast JW, Darmanyan AP, Foote CS, Diederich FN, Whetten RL, Rubin Y, Alvarez MM, Anz SJ. Photophysical properties of sixty atom carbon molecule (C60). J Phys Chem. 1991;95(1):11-2.

Ashcroft JM, Tsyboulski DA, Hartman KB, Zakharian TY, Marks JW, Weisman RB, Rosenblum MG, Wilson LJ. Fullerene (C60) immunoconjugates: interaction of water-soluble C60 derivatives with the murine anti-gp240 melanoma antibody. Chem Commun. 2006;28:3004-6.

Billes F, Mikosch H, Holly S. A comparative study on the vibrational spectroscopy of pyridazine, pyrimidine and pyrazine. J Mol Struct (Thoechem). 1998;423(3):225-34.

Burris HA 3rd, Moore MJ, Andersen J, Green MR, Rothenberg ML, Modiano MR, Cripps MC, Portenoy RK, Storniolo AM, Tarassoff $\mathrm{P}$, et al. Improvements in survival and clinical benefit with gemcitabine as first-line therapy for patients with advanced pancreas cancer: a randomized trial. J Clin Oncol. 1997;15(6):2403-13.

Chen C, Xing G, Wang J, Zhao Y, Li B, Tang J, Jia G, Wang T, Sun J, Xing L, et al. Multihydroxylated [Gd@C82(OH)22]n nanoparticles: antineoplastic activity of high efficiency and low toxicity. Nano Lett. 2005;5(10):2050-7.

Chow EK, Ho D. Cancer nanomedicine: from drug delivery to imaging. Sci Transl Med. 2013;5(216):216rv214. 
Clark DT, Kilcast D, Adams DB, Musgrave WKR. An ESCA study of the molecular core binding energies of the fluorobenzenes. J Electron Spectrosc Relat Phenom. 1972;1(3):227-50.

Clark D, Feast W, Kilcast D, Musgrave W. Applications of ESCA to polymer chemistry. III. Structures and bonding in homopolymers of ethylene and the fluoroethylenes and determination of the compositions of fluoro copolymers. J Polym Sci. 1973;11(2):389-411.

Craig NC, Evans DA. Infrared and Raman Spectra of cis- and trans-1,2-dichloro-1,2-difluoroethylene. J Am Chem Soc. 1965;87(19):4223-30.

Dawidczyk CM, Kim C, Park JH, Russell LM, Lee KH, Pomper MG, Searson PC. State-of-the-art in design rules for drug delivery platforms: lessons learned from FDA-approved nanomedicines. J Control Release. 2014;187:133-44.

Dellinger A, Zhou Z, Connor J, Madhankumar AB, Pamujula S, Sayes CM, Kepley CL. Application of fullerenes in nanomedicine: an update. Nanomedicine. 2013;8(7):1191-208.

Fang J, Nakamura H, Maeda H. The EPR effect: unique features of tumor blood vessels for drug delivery, factors involved, and limitations and augmentation of the effect. Adv Drug Deliv Rev. 2011;63(3):136-51.

Hamblin MR. Fullerenes as photosensitizers in photodynamic therapy: pros and cons. Photochem Photobiol Sci. 2018;17(11):1515-33.

Hu X-C, Zhang J, Xu B-H, Cai L, Ragaz J, Wang Z-H, Wang B-Y, Teng Y-E, Tong Z-S, Pan Y-Y, et al. Cisplatin plus gemcitabine versus paclitaxel plus gemcitabine as first-line therapy for metastatic triple-negative breast cancer (CBCSG006): a randomised, open-label, multicentre, phase 3 trial. Lancet Oncol. 2015;16(4):436-46.

Huang P, Chubb S, Hertel LW, Grindey GB, Plunkett W. Action of 2', 2'-difluorodeoxycytidine on DNA synthesis. Cancer Res. 1991:51(22):6110-7.

Kamisawa T, Wood LD, Itoi T, Takaori K. Pancreatic cancer. Lancet. 2016;388(10039):73-85.

Katritzky A, Lagowski J: 130. Infrared absorption of heteroaromatic, five-membered, monocyclic nuclei. Part I. 2-Monosubstituted furans. Journal of the Chemical Society (Resumed) 1959:657-660.

Kim BY, Rutka JT, Chan WC. Nanomedicine. N Engl J Med. 2010;363(25):2434-43.

Kleeff J, Beckhove P, Esposito I, Herzig S, Huber PE, Lohr JM, Friess H. Pancreatic cancer microenvironment. Int J Cancer. 2007;121(4):699-705.

Koay EJ, Baio FE, Ondari A, Truty MJ, Cristini V, Thomas RM, Chen R, Chatterjee D, Kang Y, Zhang J, et al. Intra-tumoral heterogeneity of gemcitabine delivery and mass transport in human pancreatic cancer. Phys Biol. 2014;11(6):065002.

Lapin NA, Krzykawska-Serda M, Dilliard S, Mackeyev Y, Serda M, Wilson LJ, Curley SA, Corr SJ. The effects of non-invasive radiofrequency electric field hyperthermia on biotransport and biodistribution of fluorescent [60]fullerene derivative in a murine orthotopic model of breast adenocarcinoma. J Control Release. 2017a;260:92-9.

Lapin NA, Vergara LA, Mackeyev Y, Newton JM, Dilliard SA, Wilson LJ, Curley SA, Serda RE. Biotransport kinetics and intratumoral biodistribution of malonodiserinolamide-derivatized [60]fullerene in a murine model of breast adenocarcinoma. Int J Nanomed. 2017b;12:8289-307.

Lee GY, Qian WP, Wang L, Wang YA, Staley CA, Satpathy M, Nie S, Mao H, Yang L. Theranostic nanoparticles with controlled release of gemcitabine for targeted therapy and MRI of pancreatic cancer. ACS Nano. 2013;7(3):2078-89.

Lumley Jones R. The infrared spectra of some simple N-substituted amides in the vapor state. J Mol Spectrosc. 1963;11(1):411-21.

Mackey JR, Mani RS, Selner M, Mowles D, Young JD, Belt JA, Crawford CR, Cass CE. Functional nucleoside transporters are required for gemcitabine influx and manifestation of toxicity in cancer cell lines. Cancer Res. 1998;58(19):4349-57.

Maeda H, Tsukigawa K, Fang J. A retrospective 30 years after discovery of the enhanced permeability and retention effect of solid tumors: next-generation chemotherapeutics and photodynamic therapy_-problems, solutions, and prospects. Microcirculation. 2016;23(3):173-82.

Motoyama I, Jarboe CH. Hydroxyl Group Stretching Frequency and Extinction Coefficient Studies on Aliphatic Alcohols. The Journal of Physical Chemistry. 1966;70(10):3226-8.

Mroz P, Pawlak A, Satti M, Lee H, Wharton T, Gali H, Sarna T, Hamblin MR. Functionalized fullerenes mediate photodynamic killing of cancer cells: type I versus Type II photochemical mechanism. Free Radical Biol Med. 2007;43(5):711-9.

Nakamura E, Isobe H. Functionalized fullerenes in water. the first 10 years of their chemistry, biology, and nanoscience. Acc Chem Res. 2003;36(11):807-15.

Palchan I, Crespin M, Estrade-Szwarckopf H, Rousseau B. Graphite fluorides: an XPS study of a new type of C-F bonding. Chem Phys Lett. 1989;157(4):321-7.

Pan Y, Wang L, Kang SG, Lu Y, Yang Z, Huynh T, Chen C, Zhou R, Guo M, Zhao Y. Gd-metallofullerenol nanomaterial suppresses pancreatic cancer metastasis by inhibiting the interaction of histone deacetylase 1 and metastasis-associated protein 1. ACS Nano. 2015;9(7):6826-36.

Raoof M, Mackeyev Y, Cheney MA, Wilson LJ, Curley SA. Internalization of C60 fullerenes into cancer cells with accumulation in the nucleus via the nuclear pore complex. Biomaterials. 2012;33(10):2952-60.

Serda M, Ware MJ, Newton JM, Sachdeva S, Krzykawska-Serda M, Nguyen L, Law J, Anderson AO, Curley SA, Wilson LJ, et al. Development of photoactive Sweet-C60 for pancreatic cancer stellate cell therapy. Nanomedicine (Lond). 2018;13(23):2981-93.

Siegel RL, Miller KD, Jemal A. Cancer statistics, 2015. CA Cancer J Clin. 2015;65(1):5-29.

Snyder JW, Lambert JD, Ogilby PR. 5, 10, 15, 20-tetrakis (N-Methyl-4-Pyridyl)-21 H, 23H-porphine (TMPyP) as a sensitizer for singlet oxygen imaging in cells: characterizing the irradiation-dependent behavior of TMPyP in a single cell. Photochem Photobiol. 2006;82(1):177-84.

Sun C, Wang L, Gao D, Pan Y, Zhao Y, Chen C, Guo M. C60(OH)22: a potential histone deacetylase inhibitor with antiangiogenic activity. Nanoscale. 2016;8(36):16332-9.

Wang L, Zhu X, Tang X, Wu C, Zhou Z, Sun C, Deng S-L, Ai H, Gao J. A multiple gadolinium complex decorated fullerene as a highly sensitive 11 contrast agent. Chem Commun. 2015;51(21):4390-3.

Watanabe S, Yoshioka H, Sakai H, Hotta K, Takenoyama M, Yamada K, Sugawara S, Takiguchi Y, Hosomi Y, Tomii K. Necitumumab plus gemcitabine and cisplatin versus gemcitabine and cisplatin alone as first-line treatment for stage IV squamous non-small cell lung cancer: a phase $1 \mathrm{~b}$ and randomized, open-label, multicenter, phase 2 trial in Japan. Lung Cancer. 2019;129:55-62. 
Watts JF. High resolution XPS of organic polymers: the Scienta ESCA 300 database. G. Beamson and D. Briggs. 280 pp.,£ 65. John Wiley \& Sons, Chichester, ISBN 0471 935921,(1992). Surf Interface Anal. 1993;20(3):267.

Xie Z, Zhang Y, Jin C, Fu D. Gemcitabine-based chemotherapy as a viable option for treatment of advanced breast cancer patients: a meta-analysis and literature review. Oncotarget. 2018;9(6):7148.

Yamakoshi Y, Umezawa N, Ryu A, Arakane K, Miyata N, Goda Y, Masumizu T, Nagano T. Active oxygen species generated from photoexcited fullerene (C60) as potential medicines: O2-• versus 1O2. J Am Chem Soc. 2003;125(42):12803-9.

Yu J, Guan M, Li F, Zhang Z, Wang C, Shu C, Wei H, Zhang X-E. Effects of fullerene derivatives on bioluminescence and application for protease detection. Chem Commun. 2012;48(89):11011-3.

Zakharian TY, Seryshev A, Sitharaman B, Gilbert BE, Knight V, Wilson LJ. A fullerene - paclitaxel chemotherapeutic: synthesis, characterization, and study of biological activity in tissue culture. J Am Chem Soc. 2005;127(36):12508-9.

Zhang Q, Yang W, Man N, Zheng F, Shen Y, Sun K, Li Y, Wen L-P. Autophagy-mediated chemosensitization in cancer cells by fullerene C60 nanocrystal. Autophagy. 2009;5(8):1107-17.

\section{Publisher's Note}

Springer Nature remains neutral with regard to jurisdictional claims in published maps and institutional affiliations.

- fast, convenient online submission

- thorough peer review by experienced researchers in your field

- rapid publication on acceptance

- support for research data, including large and complex data types

- gold Open Access which fosters wider collaboration and increased citations

- maximum visibility for your research: over 100M website views per year

At BMC, research is always in progress.

Learn more biomedcentral.com/submissions 